\title{
Bridging the Internal Gap: Special Collections and "In-Reach"
}

\section{Introduction}

OVER THE PAST DECADE, special collections professionals have attempted to break down barriers and attract new and different patrons through outreach programs to undergraduates, high school students, community groups, and others as a means of broadening our reach, widening the appeal of our materials, and ensuring our continued existence and relevance in an increasingly digital world. Our success at this endeavor can be seen in the ever-increasing rise in collaborations between faculty, students, and other members of our diverse communities written about and reflected upon in the literature. ${ }^{1}$ But while we have accomplished much with external audiences, it seems we have neglected to look closely at how we work with internal colleagues. We may collaborate with individual faculty or specific academic departments, or perhaps liaise productively with particular subject specialists or instructional librarians, but how strong are our relationships with public access, service, and reference staff? As traditionally noncirculating and closed stack repositories, our contact with circulation desks and general reference and public services may be limited, but these colleagues are often the first resort for library patrons, including potential—and actual—special collections users.

This article focuses on a reported disconnect that exists between special collections and the larger research library systems to which they belong. This issue came to the fore following a series of interviews regarding the use of off-site storage facilities by special collections departments in U.S.-based Association of Research Libraries (ARL) member libraries and, in particular, the effect that its introduction has had on public service. It became apparent during the interviews that, while as a profession we have succeeded in raising our public service profile and have improved our reputation with users through innovative outreach programs and increased instructional efforts, we are failing in one area: outreach within our own institutions to our colleagues. Through an examination of the information shared during the interviews, this article will offer insights into how this disconnect has become an important public service issue, explore questions raised about integration and collaboration in large library systems, and suggest practical solutions for combatting the problem.

1. For an overview of endeavors in this area, see in particular Matthew C. Reynolds, "Lay of the Land: The State of Bibliographic Instruction Efforts in ARL Special Collections Libraries," RBM: A Journal of Rare Books, Manuscripts and Cultural Heritage 13.1 (Spring 2012): 13-26. 


\section{Background}

At the 2013 Preconference of the Rare Books and Manuscripts Section (RBMS) of the Association of College and Research Libraries (ACRL) in Minneapolis, I co-convened a seminar titled "Conservation and Curation in the Age of Off-Site Storage: What Does It Mean for Special Collections Librarians and Conservators?"” As a follow-up to the seminar, the conveners produced a survey that was sent to the directors of special collections at U.S.-based ARL member libraries, the results of which are presented in the article "Off-Site Storage and Special Collections: A Study in Use and Impact in ARL Libraries in the United States." Within the survey, respondents were asked whether they would be willing to participate in a brief follow-up interview. In the spring of 2014, I made contact with these individuals, resulting in the scheduling of 24 follow-up phone interviews. ${ }^{4}$ Interviewees were asked a series of questions that focused on issues of public service, particularly in reference to off-site storage, the initial impetus behind the interviews. ${ }^{5}$

While the interviews had initially been planned as a means to gain more qualitative data about the central survey issue, it became significantly apparent as the conversations went on that there existed a fundamental concern regarding interdepartmental relationships within large library systems. In particular, portions of the conversations - especially those regarding the amount of liaison or connection between special collections and general reference staff-spoke to a sometimesglaring lack of communication and, in doing so, acknowledged the existence of a deep-rooted divide between special collections and other departments within the same institution.

This information was not an expected outcome, and yet two-thirds of the interviewees spoke directly about the issue, its frustrations, and possible causes. There was enough reference to the issue to indicate that this concern was both real and ongoing and therefore represented an area ripe for focus, discussion, and change within the profession. This article hopes to both encourage and support such developments through an examination of the interview data, a review of the literature on the subject, and the consideration of possible remedies or solutions.

2. Charlotte Priddle, Laura McCann, Kristen St. John, Peggy Alexander, and Patti Gibbon, "Off-Site Storage and Special Collections: What Does It Mean for Special Collections Librarians and Conservators?” RBMS Preconference, Minneapolis, June 25, 2013.

3. Charlotte Priddle and Laura McCann, "Off-Site Storage and Special Collections: A Study in Use and Impact in ARL Libraries in the United States," College \& Research Libraries (due date for publication July 1, 2015), available online at C\&RL Preprints http://crl.acrl.org/content/early/2014/09/08/crl14622.full.pdf + html [accessed 31 March 2015].

4. The interview questions were planned and interviews conducted solely by the author. It should be noted that excerpts from some of the interviews were used in the above article in $C \mho R L$; however, none of the quotes used here have been published previously.

5. See Appendix A for full interview questions. 


\section{Literature Review}

The literature on public service is robust and covers a wide range of aspects within special collections, with a strong focus on instruction and outreach, two areas that were highlighted in both the survey and interviews for their particular success in allaying potential public service problems. Special collections outreach and education efforts can be studied to gain an understanding of the types of programs used over the past decade to successfully raise profiles both within and without the academy and to examine whether the practices described within them have relevance to the issue of internal communication that is the focus of this article.

It is documented in both the literature and within the conducted interviews that the old "ivory tower" attitude of special collections has given way to an increasingly open and welcoming attitude not only toward scholars, but also undergraduates, community groups, and even $\mathrm{K}-12$ students. ${ }^{6}$ Teaching opportunities, whether characterized as the one-off session, an embedded class, or team-taught efforts between faculty and library instructors, have all been cited as examples of successful outreach to academic audiences; and the harnessing of electronic media, exhibition programs, and readers' groups have also opened the doors of special collections to audiences beyond the purely academic. ${ }^{?}$

The issue of a disconnect between special collections and the larger libraries to which they belong was raised almost two decades ago by members of the Research Collections Committee (RCC) of ARL. As the background discussions to the formation of the ARL Special Collections Initiative, the RCC came up with a series of basic perspectives on special collections. During the discussions that formed the basis of the Initiative, the RCC made a point of acknowledging the issue of the "organizational and operational isolation" of ARL-based special collections, stating that a major issue for special collections was "their very separateness, often leading to...problems with integrating special collections into the overall program of library services... and a lack of understanding and shared values between special collections and other library

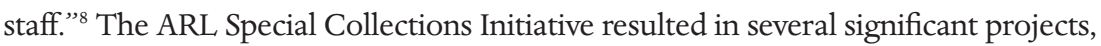
collaborations, and symposia, as well as a general effort to be more inclusive to spe-

6. See Lori Lynn Dekydtspotter and Cherry Williams Dunham, "Alchemy and Innovation: Cultivating an Appreciation for Primary Sources in Younger Student," RBM: A Journal of Rare Books, Manuscripts and Cultural Heritage 14.2 (Fall 2013): 67-81; Anne Bahde, "Taking the Show on the Road: Special Collections Instruction in the Campus Classroom," RBM: A Journal of Rare Books, Manuscripts and Cultural Heritage 12.2 (Fall 2011); 75-88; Reynolds, "Lay of the Land."

7. See Michelle Visser, "Inviting the Rabble In: Changing Approaches to Public Service and Access in Special Collections," in Public Services Quarterly 1.4 (2003): 29-41; Daniel Traister, "Public Services and Outreach in Rare Book, Manuscript and Special Collections Libraries," Library Trends 52.1 (Summer 2003): 87-108 for examples of these and other efforts.

8. Joe A. Hewitt and Judith M. Panitch, “The ARL Special Collections Initiative," Library Trends 52.1 (Summer 2003); 151-71. 
cial collections, particularly through their agenda to emphasize special collections as a "fundamental and indispensable part of the research library mission." however, were necessarily aimed at a broad and high level and did not include specifics as to the terms upon which special collections could be better integrated.

In their work on special collections instruction, Jason Tomberlin and Matthew Turi build on the notion of integration by suggesting more concrete ways in which special collections professionals can work within their home institutions. Necessarily focused on teaching, they suggest a program of collaboration including sitting on institutionwide committees and other instructional-based efforts, stating that instructional colleagues in particular "can, if properly trained and informed about special collections resources, serve as referrals for both student research and instructor needs." ${ }^{10}$ Again, however, the focus is on bringing students and faculty into special collections; while it mentions the need to "in-reach" to colleagues, it is narrowly focused on improving instructional programs, rather than wholesale or general interdepartmental outreach. ${ }^{11}$

Daniel Traister, in his 2003 article, sheds light on different modes of outreach that special collections can use to "promote" their collections. ${ }^{12}$ These efforts include many of those indicated above, such as exhibitions, instruction, digital efforts, seminars, and discussion groups hosted by the library, invitations to creative writers, instigating friends groups, and reference. It is in this latter part that Traister comes closest to addressing the issues raised by the RCC, noting that the skills needed by general reference staff have changed radically during the preceding few years and that the "traditional" skills needed for much special collections research are no longer necessarily part of their expanded skill set. Recognizing this capability is important for the special collections professional, as Traister makes clear: "by not condescending to those colleagues whose expertise necessarily takes them increasingly in other directions, some potential internal problems can be avoided while the advantages of such service are enjoyed." ${ }^{13}$ A respect for the area expertise of both general reference and special collections staff should be expected from professionals; it is easy to read between the lines of Traister's statement on not condescending to reference colleagues and imagine exactly this type of scenario occurring. This can be a two-way street, especially in the decade since Traister wrote his article and the huge growth in electronic resources that has occurred in the ensuing period, an area in which special collections staff may perhaps have less all-round expertise than general reference or subject specialist public service staff.

\footnotetext{
9. Hewitt and Panitch, "The ARL Special Collections Initiative," 165.

10. Jason Tomberlin and Matthew Turi, "Supporting Student Work: Some Thoughts about Special Collections Instruction," Journal of Library Administration 52 (2012); 304-12.

11. Tomberlin and Turi, "Supporting Student Work," 310.

12. Traister, "Public Services and Outreach."

13. Traister, "Public Services and Outreach," 102.
} 
Valerie A. Harris and Ann C. Weller also speak to the promotion of special collections, albeit to an academic audience, through varied means, defining outreach as "the proactive endeavors by special collections staff to increase awareness and use of their collections and the professional mission of special collections librarians and archivists, both within and outside the academy." ${ }^{14}$ Again, most of the emphasis is on potential readers - students, faculty, and other patrons - through the diverse means described previously, adding social media into the mix. The article also mentions reference, referring to a 2010 survey regarding reference service as being the most important factor in user satisfaction, suggesting that "nonexpert staff" need to be able to know enough to identify when the research query should be passed on to experts. ${ }^{15}$ This is another argument for ensuring that special collections staff retain the specialized knowledge regarding both their own collections and the tools necessary to aid research into them, but it does not address either the issue of liaising with general reference staff to ensure a smooth transition for the patron or the types of training general staff need to have in order to know when to pass the patron on to special collections.

This aspect of public service - ensuring a good experience for any patron, regardless of whether they are special collections readers or not-is one of the points made by Michelle Visser, arguing that, regardless of research need, patrons need to be helped and special collections professionals must do their best to address these needs, even when out of their area of expertise. ${ }^{16}$ Visser goes on to state how this kind of general help "counteracts stereotypes of the rude or unhelpful librarian... it ensure[s] that students receive the help they need and it avoids the problem of their getting lost, physically and metaphorically, in the shuffle to another department." ${ }^{17}$ This kind of action is one more way to avoid the possibility of the unsatisfactory special collections transaction, which can, as Harris and Weller state, "have a lasting negative effect on the perception of special collections departments and librarians." 18

\section{Interview Responses ${ }^{19}$}

Special collections can exist in a mixture of different spaces, configurations, and administrative units. The collection may be physically located within the main library structure or housed separately in its own building. There may be several separate special collections with individual collecting scopes and missions within the system,

14. Valerie A. Harris and Ann C. Weller, "Use of Special Collections as an Opportunity for Outreach in the Academic Library," Journal of Library Administration 52 (2012): 296.

15. Harris and Weller, "Use of Special Collections," 299.

16. Visser, "Inviting the Rabble In," 33.

17. Visser, "Inviting the Rabble In," 34.

18. Harris and Weller, "Use of Special Collections," 295.

19. All quotes are taken from interviews conducted by the author between May 12, 2014, and June 18, 2014. Quotes from interviews are prefaced with reference to their origin; quotes from published articles are cited in the endnotes. 
or collections may have been consolidated into one larger department in a single physical space. Regardless of the specifics, special collections within academic institutions remain part of a larger library system, even though levels of integration and shared services may vary. What became apparent through the interviews, however, was that special collections remain in many ways separate or "other" to the larger library system and are often viewed as such by other departments. The question then becomes: how do special collections professionals bridge this internal gap between themselves and the rest of the library?

The existence of a disconnect seemed to be especially true between public service and access departments, particularly general reference desk staff, and the archivists and librarians within special collections: 16 of the 24 interviewees noted issues in their relationships with colleagues in public access/reference, ranging from bad referrals to the wrong information being shared with patrons. Of major underlying concern, however, was the acknowledgment that awareness regarding special collections in general—what they are and what they do-was lacking.

The necessary separateness of special collections is part of the cause of this problem. The view of them as "treasure rooms" containing items not to be touched or used, guarded by "gatekeepers" is an historical perception that may have changed in practice, but it has a lingering presence. Tours of the general library, led by instructional or other staff, often cannot get access to special collections areas due to the size of the group, time constraints for the tour itself, or the hour at which it is scheduled. This is, of course, when the special collections are on the tour schedule at all; the lack of awareness or understanding of them and what they hold within can either lead to omission from itineraries or admissions of mystification as to what happens inside them. ${ }^{20}$ Understandably, being presented with a locked door behind which lurk "rare books" or "manuscripts" that are literally out of reach and that may never have been seen by the tour leaders, even if fellow librarians, does not do much to integrate special collections with the rest of the library system or with the people conducting the tours. While some interviewees mentioned that they had themselves conducted tours for incoming public service colleagues, in an attempt to broaden understanding of their departments, for many it seemed that special collections were just "not on the agenda" for tour leaders from other departments, to quote one interviewee. This was true even, as one noted, when touring student groups, a factor that exacerbates the separateness.

20. The author herself once witnessed a tour for incoming students that stopped outside the door of the department. The staff member leading the group stopped, pointed at the closed glass doors, and announced, "This is special collections. I don't really know what they do in there"-and then led the group up to the next floor. 
Eight interviewees made a point of noting specifically how the lack of knowledge about special collections, the "mystification factor" or "foreign-ness" of them, was reflected in the relationship and communication between their departments and reference staff. The interviewees acknowledged a fundamental knowledge gap and the effect it had on the success of public service efforts as a whole. As one interviewee stated, "I don't think that the general reference staff as a whole has much of an awareness of special collections materials and use," and another, "despite attempts, [reference staff] don't really get how things are different in special collections." The gap was also recognized as having been present for a while; one interviewee noted that they had been working on the issue "forever," while another noted that the lack of knowledge had the effect of leading to misinformation being communicated to patrons: "[we have] had challenges with bad referrals in the past few years... there's a lot of different staff working on desk so it is really hard to know referrals are happening properly."

There was a perception that this unknown-ness factor in regard to special collections also resulted in a tendency among general reference staff to send patrons directly to the department as soon as the phrase "archives" or "special collections" was used. Rather than attempt to answer any question, general reference staff were perceived to simply send people on their way immediately, either through a lack of knowledge or a fear of getting the answer wrong: "reference staff feel like they don't know and just [send] people straight upstairs...they have the sense that it is so foreign upstairs in special collections... [they] don't trust themselves to give answers even though it is online."

This dislocation between special collections and public services or reference departments may be a symptom of how those departments are themselves staffed: many of the interviewees described the high turnover of circulation and/or reference staff, as well as the use of students and other part-time workers in such positions. Despite frustrations, there was an acknowledgement of the huge amount asked of reference staff, both in terms of in-person queries and online interactions. Dealing with questions regarding all aspects of library functions, from simple directional or practical issues to in-depth research queries, mean that reference and public services staff can easily become inundated. When such positions are staffed by student assistants or experience a high turnover, a tendency to not delve too deeply into all nuances (particularly when a specific department can better handle such questions) becomes more understandable. As one interviewee stated, "[we] have tried to meet with new reference staff and post on their listserv as a reminder, but so much information is coming at them that sometimes they forget and as soon as they hear 'special collections,' they send them elsewhere." 
Passing patrons on to special collections may result in more specific information being communicated to the patron; but, when the reading room is closed, or the patron needs the information immediately, the lack of clear communication between departments can lead to misinformation being passed along. One interviewee raised this, saying that $\mathrm{s} /$ he encountered patrons who have been to the general reference desk and yet are unaware of the operations of special collections: "[we] often get researchers walking in who have been to the reference desk who don't know that stuff is non-circulating." In reference to specific cases, one interviewee stated: "They don't necessarily have an idea of what is off-site—if at all—and I'm not sure that patrons get a consistent answer at the main reference desk." Changes in workflows in special collections, such as the adoption of off-site storage for their materials, must necessarily be communicated outside the department by special collections themselves. Lack of knowledge of such changes by non-special collections staff makes the worst-case public access scenario-a patron being told something is available only to discover in the reading room that it is not-an actual reality.

The ongoing issue reflected on in these interviews spoke largely to a problem that had been encountered for years but that had perhaps been thrown into starker relief due to such relatively recent changes in internal workflows as off-site storage and the expansion of collections within large research libraries. Special collections departments obviously have some level of culpability in this problem. One interviewee talked of the "real disconnect between what reference staff do and the information [provided] from special collections," obliquely referencing an understanding of the need for special collections departments themselves to start tackling the problem and gain an understanding of how to work better with colleagues.

\section{Potential Solutions}

Educational efforts by special collections have increased the use of materials across academic departments, as seen. Relationships with instructional colleagues have been of particular focus in the past decade, due to the interest in expanding that role within special collections. Several interviewees spoke about how working on instructional programs cross-departmentally had helped in the "demystification" process, albeit on a small scale. In these days of static or shrinking budgets, working to create a cross-departmental instruction/outreach/reference position may be a way of mitigating both the burden of instruction from staff already overstretched and simultaneously easing the misinformation and mystification issue. One interviewee noted the creation of such a dual-reporting position, with duties both in special collections instruction and the main reference instruction group, enabling an awareness of issues and the ability to present information to both groups. 
However, while such dual instruction/special collections roles may help in outreach to faculty and students for teaching purposes, there is no assurance that this will trickle down into better, universal knowledge of special collections as a whole. Combined subject specialist and special collections positions may similarly aid integration in some capacity, but, as one interviewee noted, while people who work in such positions have considerable interplay, "it is all about what you do $90 \%$ of the time." Differences in library administrative and departmental reporting structures also mean that not all institutions are willing or able to implement such hybrid positions. Adoption of the liaison model noted by one respondent may have the potential to make inroads into interdepartmental collaboration, facilitate closer contact between departments that perhaps have not traditionally worked together, and support better communication channels. In this case, the interviewee stated, "liaisons do produce that message, but [we] still have a lot of work to do," a description that highlights the need for ongoing institutional effort rather than the "quick-fix" approach.

The experience of using instruction efforts as a means of outreach into academic departments can perhaps be adopted as a successful model to replicate internally. When asked about methods of combatting the disconnect, one interviewee said: "[we] work with Orientation folks and Instructional Generalists to bring people onto campus... have them come into Special Collections and look at stuff and get them engaged straight away. This helps the Public Services people know about that extra connection and the links between the departments." This extends the instructional program inward, inviting colleagues to get as excited and knowledgeable about the materials in special collections as the students and faculty that these efforts were initially directed toward. Another interviewee talked about how they "offer in-house training sessions for employees every year called 'de-mystifying special collections' that anyone can come along to."

These examples represent an important step and can go a long way to increasing special collections visibility and openness. At New York University, introductory tours for new staff have mainly happened on an ad hoc basis, dependent on the staff member conducting the orientation tour to have a person within special collections to contact. When this has occurred, it has been successful; but, when it has not, the department has been left off the agenda completely. After recognizing the issue during the past year, incoming librarians and other full-time staff have been invited for either one-on-one or small-group tours of the department, giving them a chance to not only meet special collections staff but also see the operation of the reading room and go behind the "closed doors" of the stacks. Such tours take time, but efforts to both describe the workings of the department and to find something that might be of direct professional interest to new colleagues (such as 
antique maps for the new GIS librarian or early works on evolutionary science for the incoming Life Sciences librarian) have allowed us to both introduce ourselves as colleagues and bring out aspects of the collections that may be useful either for their own research or for students or faculty that they serve. It also gives us the opportunity to communicate directly the most important aspects of how the collection works: hours, days of operation, where collections are stored, and what patrons have to do to get access.

Administrative or strategic initiatives can also be of help; one interviewee spoke of a standing committee on information literacy being required to include a member from Special Collections. Such committee work represents an aspect of collaboration that can speak to institutional, departmental, and personal goals. Committee participation helps break down perceived barriers, mixes members of different departments together, and serves to unite disparate colleagues around topics that are often of interest to them all, albeit from different perspectives. The simple fact of seeing the same face from a previously unknown department and knowing who that person is and who they represent can help in encouraging interdepartmental communication, providing a contact or "point" person for questions and assistance. For many professionals, including me, committee work and service to the library are a necessary part of promotion; this perhaps forced necessity can be fundamental to building bridges with colleagues. Successfully serving on one committee often leads to appointment to another and represents the means for individual staff members within special collections to gain a greater presence within the library as a whole. Becoming the "go-to" person within a department can initially seem burdensome, but it represents an opportunity to expand knowledge of the department while enabling a forum for information sharing that can reap benefits across the board. After appointments on two library faculty committees, I was asked to join a larger strategic initiative team examining instruction within my institution; this appointment led to the development of strong ties with instructional colleagues at the undergraduate level and other areas of the library. Another outcome was a "brown bag" lunch in our exhibition space attended by colleagues from across departments including access and delivery services, subject specialists, reference staff, instructional staff, and fellow special collections librarians and archivists. This event proved to be the first time many of the staff-particularly those in public services, many of whom had worked in the library for years-had ever been up to special collections. This open house served as the beginning of a process to give staff outside the department a chance to understand the collections, gain a sense of their accessibility, and realize that we were more "open" than perhaps expected or previously experienced.

One interviewee stated that working with public services heads and participating 
in their meetings helped in getting specific information across to frontline staff. The means of sharing was vital also: as discussed, general reference staff can have almost too much data at their fingertips. Finding a way to provide information that can be easily used is reliant on dialogues happening with the staff themselves and ensuring that what is provided is clear and accessible. These dialogues can make the transaction with a potential special collections patron less scary for the reference staff and result in a reduction in the "bad referrals" commented on by interviewees.

It is important to acknowledge also that the communications gap works in both directions: special collections staff also suffer from the lack of integration. Concentrated efforts to join either general reference discussion groups or to participate in librarywide outreach opportunities, such as staffing "Welcome Week" tables for incoming students together with public services staff, offer a means to break down the view of special collections as somehow separate and unconnected and allow a space for informal information exchange that can only help both parties. Special collections staff that can address general queries from patrons, including those who just wander into the repository, in a helpful, sensitive, and correct manner can help reduce general library anxiety and negate the sense of unease many students feel when mistakenly ending up in what seems a rarified atmosphere. While it is not expected that all special collections staff will necessarily have an in-depth knowledge of all aspects of the library, from e-resources to printer locations, making attempts to help all users before directing them on to those who may have greater knowledge not only conveys a general air of willingness to help but also communicates a sense of that librarian/archivist belonging to the library as a whole. This does not change the separate skills the special collections professional needs in any way; what it does is help the special collections staff seem a little less remote and is a model that can be encouraged in general reference staff.

\section{Limitations of Study and Suggestions for Further Research}

Drawn from the original survey population of directors of special collections in US-based ARL member libraries, the data presented in this article are admittedly from a specific and relatively small sample type. While this does not negate the significance of the findings or the likelihood that similar disconnects occur in other large library systems that have special collections or other such focused yet separate repositories within them, it does suggest that further research around this topic outside the initial study needs to be conducted to get a broader understanding of this issue.

Research also needs to be done into the experience of disconnect by staff lower down the administrative hierarchy. These colleagues, who work with patrons and deal directly with the potential miscommunications and problems that arise from 
them, must inevitably have thoughts on the subject and experiences that are relevant to the planning and implementation of solutions. Conducting a similar series of interviews with such staff that would both focus on the results of such disconnects and provide examples of possible or actual solutions enacted by them would give a more concrete baseline of data from which to potentially plan administrative actions. Combining such interviews with those in general public services positions outside special collections would also add a valid and important balance to the special collections viewpoint. Another possible area of immediate research would be to ascertain how (or if) those colleagues in hybrid positions, with split reporting or joint responsibilities across special collections and general public services/instruction, have indeed managed to bridge the communications gap and find better ways of integrating colleagues across departments. ${ }^{21}$

\section{Conclusion}

As a profession, we have changed the perceptions of special collections radically in the past decade for patrons, students, and faculty. Perhaps we have been so focused on external programs that we have not concentrated on internal promotion, which has less immediate, measurable results. While initially concentrated on the impact of off-site storage of our materials, data from the interviews brought into focus an issue that may have been around for years but that has been brought to the fore due to ongoing changes in the "traditional" working modes of special collections. Awareness of this deeper communications gap allows us as a profession to be more cognizant of how we operate within our own institutions, of the nuances of influence that new trends in workflow have on policies and procedures and how we share information, and enables us to attempt to find solutions to these problems.

Over the course of the interviews, it was apparent that there had not been any formally defined or programmatic initiatives to internal colleagues in the same manner as has been seen with outreach efforts to potential users; and yet, given the scope of the problem, this seems to be exactly what is needed. As one interviewee categorically stated, "I don't think there has been as much of a dialogue as there should be." As a profession, we responded to earlier calls to "bridge the gap" that separated special collections from students and other potential external audiences; it is now beholden on us to do the same on an internal basis. ${ }^{22}$

Potential solutions to the issue offered by some of the interviewees covered a range of areas to explore; but, from these conversations and reflections on personal expe-

21. An example of these "blended positions" is examined in Liz Mengel's article, "The Confluence of Collections at Johns Hopkins's Sheridan Libraries," Research Library Issues: A Report from ARL, CNI, and SPARC, no. 283 (2013): 26-30.

22. Deirdre C. Stam, "Bridge that Gap! Special Collections and Education," RBM: A Journal of Rare Books, Manuscripts and Cultural Heritage 7.1 (Spring 2006): 16-30. 
rience, it seems that the most successful rely on a combined approach of increasing the visibility of special collections staff within the general library and opening the doors of the department not just to patrons but also to colleagues in a systematic and sustained way. This type of approach needs a constant commitment from staff regardless of administrative position as well as administrative support, either through strategic planning or other integrative programs. It necessarily involves obligations of time both from individual special collections professionals who need to find space in their calendars and from the department as a whole, who must view the project as an ongoing obligation to their institution. If, as Traister stated in 2003, we have "an imperative to make...collections increasingly user-friendly, functional, and actively used parts of the larger library," then we need to make "the larger library" part of our audience, viewing our colleagues as both partners and potential patrons, and a new audience for this dedicated "in-reach." ${ }^{23}$

\section{Appendix A: Interview Questions}

1. What type of off-site storage system does your special collection use?

2. Do you store archives and books off-site?

3. In the survey results, off-site storage was shown to have the biggest impact on public service. Are you surprised by this result? Would you agree that in your collection, this is true?

4. How does your catalogue indicate to the user that materials are offsite? Do you think this is clear?

5. How are materials recalled - are they mediated by Special Collections staff, or can the user remotely recall items via an online request?

6. How long does it take for materials to be delivered to the reading room from the time they are requested?

7. Do you think that the issue for users is the length of lag-time or does the wait time not make any difference, i.e. is it the fact that the materials are not there that causes the problem?

8. Do you or have you, or your staff, engaged with reference and/or public access staff within the general library regarding the specific aspects of recalling off-site materials for special collections?

9. Is there a section of your user community that you feel has been impacted more severely by off-site storage? How have you been combatting this concern?

10. Any other comments? 